IRA-International Journal of Education \&

Multidisciplinary Studies

ISSN 2455-2526; Vol.17, Issue 01 (Q1, 2021)

Pg. no. 35-44.

IRA Academico Research

\title{
A Review of the Overseas Communication of the Romance of the Three Kingdoms
}

\author{
Jia Fang ${ }^{1}$, YanFang $\mathrm{Hou}^{2 \#}$ \\ ${ }^{1}$ Postgratuate Student of the School of Foreign Studies, Yangtze University, Hubei, P. R. China. \\ ${ }^{2}$ Associate Professor of the School of Foreign Studies, Yangtze University, Hubei, P. R. China.
}

\# corresponding author

Type of Work: Peer Reviewed.

DOI: 10.21013/jems.v17.n1.p5

DOI URL: https://dx.doi.org/10.21013/jems.v17.n1.p5

\section{How to cite this paper:}

Hou, Y., Fang, J. (2021). A Review of the Overseas Communication of the Romance of the Three Kingdoms. IRA-International Journal of Education \& Multidisciplinary Studies (ISSN 2455-2526), 17(1), 35-44. DOI: https://dx.doi.org/10.21013/jems.v17.n1.p5

(C) IRA Academico Research.

(cc) B EY-NC This work is licensed under a Creative Commons Attribution-NonCommercial 4.0 International License subject to a proper citation to the publication source of the work.

Disclaimer: The scholarly papers as reviewed and published by IRA Academico Research are the views and opinions of their respective authors and are not the views or opinions of IRA Academico Research. IRA Academico Research disclaims of any harm or loss caused due to the published content to any party.

IRA Academico Research is an institutional publisher member of Publishers International Linking Association Inc. (PILA-CrossRef), USA. IRA Academico Research is an institutional signatory to the Budapest Open Access Initiative. Hungary advocating the open-access of scientific and scholarly knowledge. IRA Academico Research is a registered content provider under Open Access Initiative Protocol for Metadata Harvesting (OA/-PMH).

The journal is indexed \& included in WorldCat Discovery Service (USA), CrossRef Metadata Search (USA), WorldCat (USA), OCLC (USA), Open J-Gate (India), EZB (Germany) Scilit (Switzerland), Airiti (China), Bielefeld Academic Search Engine (BASE) of Bielefeld University, Germany, PKP Index of Simon Fraser University, Canada. 
ABSTRACT

The novel the Romance of the Three Kingdoms (Sanguo yanyi 三國演義) stands out among the most famous and influential works in Chinese literature. It was read by readers from all levels of society from the Emperor down all over the world. At present, most researches of the Romance of the Three Kingdoms focus on its English translation and its communication in a certain country, especially concentrated in neighboring countries or regions surrounding China, such as Thailand, Japan and so on. In order to provide researchers with a comprehensive and systematic review about its spread and impact, this research intends to investigate the current communication situation of the Romance of the Three Kingdoms in various countries from three aspects of communication form, communication strategies and communication effect. Then it is found that the overseas communication of the Romance of the Three Kingdoms has diversified forms and various communication strategies, but there are still some deficiencies and problems in the process of overseas communication. In order to solve these problems, this paper puts forward corresponding suggestions from the perspectives of "communicator", "communication content" and "communication channel", with an aim to provide some reference for the overseas communication of the Romance of the Three Kingdoms.

Keywords: The Romance of the Three Kingdoms, communication studies, communication effect.

\section{Introduction}

The Romance of the Three Kingdoms has been given a lot of fame in the history of Chinese literature, such as the originator of Chinese historical novels and one of China's four great classics. Moreover, it is one of the earliest Chinese classical novels to go abroad and spread in the world, exerting a great influence on world literature. This article analyzes its current communication situation in various countries and provides a reference for the optimization research of the Romance of the Three Kingdoms to promote Chinese literature to go out better.

\section{The Overseas Communication of the Romance of the Three Kingdoms}

The Romance of the Three Kingdoms has been widely disseminated abroad in various forms, together with its different influence in Asia, Europe and America. This section clarifies its communication and effect in different countries and regions based on communication form, communication strategies and communication effect.

\subsection{Diverse Forms of Communication}

\subsubsection{Forms of textual translation}

The Romance of the Three Kingdoms, written by Luo Guanzhong in the 14th century, is a historical novel. It has not only become an integral part of Chinese culture, but also has been widely read all over the world, especially in Japan, Korea, and Vietnam. As early as 1569, the novel was disseminated to North Korea. In 1635, the Romance of the Three Kingdoms(《三国志传》) was collected in the Oxford University Library in England. The amount of its abridged translation and complete translation in Asia, Europe, and America is more than 60 kinds (Bo, 2009). The following part introduces its textual translation and publication in different countries or regions, 
including a detailed description in Asian countries: Japan, Korea, Vietnam, Thailand, Malaysia, as well as a brief introduction in Europe and America.

\section{(1) Japan}

In Japan, Popular Romance of the Three Kingdoms (《通俗三国志》), which was translated by Wenshan of Hunan (a joint name of the two monks Yizhe and Yuetang of Tenryuji Temple in Kyoto) and that was published between 1689 and 1692, was the world's first foreign version of the Romance of the Three Kingdoms. The 50-volume book had a great influence on the popularity of the Romance of the Three Kingdoms in Japan. Because of its popularity, it lasted 12 years from Tenbao Qi (1836) to the publication of the picture book Popular Romance of the Three Kingdoms( 《绘本通俗三国志》), which was edited by Ikeda Tori-tei and illustrated by Katsushika Daito. Katsushika Daito is the most famous Ukiyo painter Katsushika Hokusai's outstanding apprentice. Due to these factors, it sold well. The publication and popularity of this picture book expanded the readership to the level of ordinary people.

\section{(2) Korea}

The Romance of the Three Kingdoms was disseminated to Korea in the middle of the 16th century during the period of Korean king of Xuanzu, (Guo \& Luo, 2014). In terms of book publishing, many Korean versions of the Romance of the Three Kingdoms appeared. Among them, many Korean writers, such as Piao Zhonghe, Li Wenlie and Jin Hongxin, rewrote the Romance of the Three Kingdoms based on Luo Guanzhong's version, which promoted Koreans to understand the historical figures, events, royal family, official system, education system and customs in the late Eastern Han Dynasty and the Three Kingdoms Period of China. In addition, various cartoons of the Romance of the Three Kingdoms, which were played successively for children, teenagers, and adults since the 1970s, had also become an important medium for Koreans to understand ancient Chinese history and culture.

\section{(3) Vietnam}

In 1907, the Saigon Opinion Printing House (Imprimerie de l'opinion) published the first translation of the Romance of the Three Kingdoms in Vietnam in the form of book, translated by Nguyễn Liên Phong, Nguyễn An Cư, and Nguyễn An gừng. This version comprises 31 volumes, each with its own illustrations. In 1909, the Hanoi Express Printing House (Imprimerie-Express) published the translation of the Romance of the Three Kingdoms translated by Phan KếBính and edited by Nguyễn Văn Vĩnh. It was the first translation edition of the Romance of the Three Kingdoms that came out in the north. In 1928, Xinde Publishing House (TínĐức thưxã) republished Nguyễn An Cư's translation of the Romance of the Three Kingdoms. Then the version translated by Nguyễn Chánh Sắtwas published in Saigon in 1930. In 1933, Hanoi Xinmin Bookstore published a translation of Nghiêm Xuân Lãm. In 1949, Nhàin Phúc Chi in northern Vietnam published a version of Hồng Việt. In the late 1950s and early 1960s, Hanoi General Publishing House (NXB PhổThông) published a translation of the Romance of the Three Kingdoms translated by Pan Jibing and edited by Bùi Kỷ, totaling 13 volumes. It is worth mentioning that this version was carefully edited, together with illustrations. In 1960, Asia Publishing House (NXBÁChâu) in South Vietnam published Tử Vi Lang's edition of the Romance of the Three Kingdoms. Later in 1966, NXB Hương Hoa published the translation of Mộng Bình Sơn, printed only approximately 1,700 pages in a volume. Due to political 
and social factors, the translation and publication of Chinese novels in Vietnam entered a relatively "cold" period after 1975. Until 1987, the University and Vocational Middle School Press (NXBĐại học vàGiáo dục chuyên nghiệp) republished the translation of the Romance of the Three Kingdoms based on the 1909 printing plate of the general publishing house. It was divided into 8 volumes. In addition to the map, it also included a comparison table of ancient and modern place names. Since then, the publication of the Romance of the Three Kingdoms had become more extensive and frequent. Especially in 2007, the Vietnamese Literature Publishing House published the 1959 translation edition again. This edition had illustrations and also included a chapter about the Formation of the Romance of the Three Kingdoms in Vietnam, which counted every publication and introduction of the Romance of the Three Kingdoms in Vietnam (Mo, 2017).

It can be seen that the Romance of the Three Kingdoms is a well-known novel in Vietnam. It has not only influenced the social activities and customs in Vietnam but also affected the creation of its literature (Yu, 2020).

\section{(4) Thailand}

In 1802, in order to revive the declined Thai classical literature due to the fighting of the Thai-Burmese War, the King of Bangkok ordered the famous poet Chaophraya Phrakhlang (Hon) to preside over the translation of the Romance of the Three Kingdoms and made it an important measure to prosper Thailand's National Literature, which promoted the publication of Samkok, the first Thai translation version of the Romance of the Three Kingdoms. In the following two hundred years, Samkok gradually spread in Thailand, and it was adored and praised highly by Thais. During the period of Bangkok King Vajiravudh, Hong's version of the Romance of the Three Kingdoms was rated as "the crown of prose stories" by the official authority "Thailand Literature Club" at that time. Some chapters, such as "Borrowing Arrows With Thatched Boats" and "Burn The Linked Camp", were later selected into Thai textbooks for Thai secondary schools. After Hong's version of the Three Kingdoms, Thailand later released many rewritten versions of the Three Kingdoms, including various translations, adaptions, imitations and re-creations (Jin, 2013).

\section{(5) Malaysia}

Baba Malay translation text of the Three Kingdoms (Sam Kok) which first appeared on the Malay Peninsula was translated by the outstanding translator, Penang Baba Tsang Jinwen, and was gradually published in 30 volumes in Singapore from 1892 to 1896. In 1992, the Shifang Publishing House in Malaysia published a Malay comic the Romance of the Three Kingdom: the Story of the Three Kingdoms [Riwayat Tiga Kerajaan (Sam Kok)]. On May 17, 2012, the launching ceremony of the Malay translation of the Romance of the Three Kingdoms was held at the National Language Publishing Bureau of Malaysia (Han, 2015). Owing to the joint efforts of publishing houses and the government, the Romance of the Three Kingdoms was widely disseminated in Malaysia.

\section{(6) Europe and America}

The first English translation of the Romance of the Three Kingdoms was The Death of the Celebrated Minister Tung-chu, which was translated by P. P. Thomas of the United Kingdom. This translation was published in the Asiatic Journal in 1820 and 1821, whose detailed content was the translation of the Romance of the Three Kingdoms from the first chapter to the ninth chapter (Wang, 1988). It was abridged translation when the Romance of the Three Kingdoms was circulated in Europe 
and America in the early days. The English translation of the Romance of the Three Kingdoms in the 19th century went from abridged translation to chapter translation with its translation mainly published in the journals (see Table 1, this table was organized based on the relevant articles). The translation text and comments were intertwined, which promoted the communication of the Romance of the Three Kingdoms. On the whole, Chinese literature are disseminated in North America mainly through three channels: The first is by means of the translation of Chinese literature; the second is via the communication of media and journals; the third is through Chinese studies (Wu , 2018).

\subsubsection{Non-text forms of communication}

At present, the Romance of the Three Kingdoms has various forms of non-text communication overseas, including oral transmission, opera, TV drama and games.

The Romance of the Three Kingdoms spreads in various forms in Southeast Asia, including rap artists' performance, scripts and dramas, films and TV series, and many vivid games in Japan and South Korea. The diversification of communication channels has laid the foundation for the communication of the Romance of the Three Kingdoms (Guo \& Luo, 2014). In Vietnam, the Romance of the Three Kingdoms also has various communications as poetry, poetic drama and opera in Thailand. The Romance of the Three Kingdoms has more diverse forms of dissemination in Malaysia, including special lectures and seminars besides the above forms. The television media plays a very an important role in promoting the spread of the Romance of the Three Kingdoms in Malaysia.

Table 1: List of Translations and Introductions of the Romance of the Three Kingdoms in English journals (1800-1911)

\begin{tabular}{|c|c|c|}
\hline English journals & Publication time & Translation of Three Kingdoms \\
\hline Asiatic Journal & $1816-1845$ & Three Kingdoms (P. P. Thomas) \\
\hline Chinese Repository & $1832-1851$ & Three Kingdoms \\
\hline Journal of the Royal & $1834-1990$ & \\
Asiatic Society & & Three Kingdoms \\
& & \\
\hline The Phoenix & $1870-1873$ & Three Kingdoms(GG Alexander) \\
& & \\
\hline
\end{tabular}




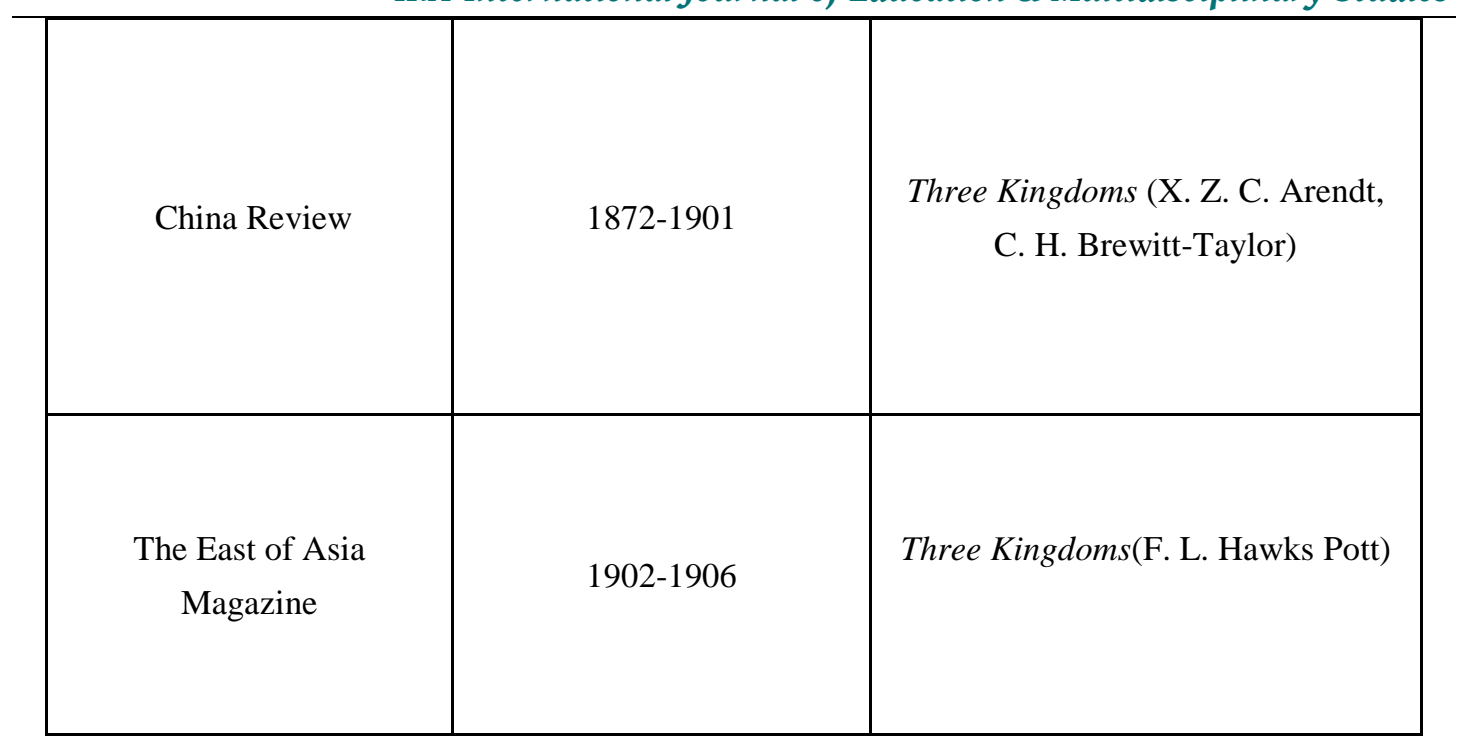

Note: Three Kingdoms in Table 1 refers to the Romance of the Three Kingdoms.

In 1994, the Malaysian state-run TV station introduced the Chinese TV series the Romance of the Three Kingdoms with Malay subtitles. In 2010, Malaysia Astro Supreme HD (3) launched a new version of the TV series "Three Kingdoms"(2010 version). As soon as it was broadcast, the play received an enthusiastic response and sparked audiences' crazes of watching it (Han, 2015). The multimodal communication method has made the Romance of the Three Kingdoms popular and adored by people in Southeast Asia.

Similarly, the Romance of the Three Kingdoms also has multiple forms of communication in Western countries. In recent years, the Romance of the Three Kingdoms has also entered European and American countries in the forms of dramas, movies, and online games, and the response has been enthusiastic. In 2012, the Peking Opera "Red Cliff" created by the National Centre for the Performing Arts was successfully toured in the three European countries: Vienna, Budapest and Prague. The film "Red Cliff" directed by John Woo was recognized and accepted by audiences in Europe and the United States. What's more, the online games of the Three Kingdoms were very popular among young people in Europe and America (Chen, 2017), such as Total War: Three Kingdoms.

\subsection{Communication Strategies}

The Romance of the Three Kingdoms has been widely disseminated in countries around the world and has been loved by people from all over the world, especially in Asia. Its dissemination strategy has extremely important reference significance for Chinese culture to go out.

Many factors promote the wide communication of the Romance of the Three Kingdoms in Thailand (Yang \& Deng, 2011), such as the success of its creation, the love of Chinese classical literary works by a large number of Thai Chinese and ethnic Chinese and Thai royal family members, as well as the diversification of communication channels. Sinologists promote the communication and acceptance of Chinese literature overseas through various cooperative and interactive means, such as cooperation with sinologists, cooperation with Chinese scholars or overseas Chinese, and cooperation with Chinese writers. Furthermore, sinologists' researches on Chinese literature can form a positive interaction with domestic researches, thus promoting Chinese literature to go out better (Cao, 2017).

The overseas communication of the Romance of the Three Kingdoms has the following characteristics: diversified forms of communication, multiple levels of communication subjects, 
diversified communication channels, and different communication strategies for audiences. The effective enlightenment of its overseas communication on contemporary literature is that the overseas communication of literary works not only needs diversified forms of communication, multi-level communication subjects, and diverse communication channels but also requires common values, innovative communication carriers and showing public care (Chen,2017). Currently, the spread of the Romance of the Three Kingdoms is mainly spread through multiple channels and platforms. What's more, the quality of the communication strategy can be investigated through the effect of communication.

\subsection{Communication Effect}

The Romance of the Three Kingdoms is adored by Asians (Ren et al, 2006), so its communication effect is pretty good in Asia. However, the communication effect in Western countries cannot as good as that in Asia due to the cultural difference.

As a representative work of ancient Chinese novels, the Romance of the Three Kingdoms soon spread to neighboring countries, such as Japan, Korea and Vietnam after its creation, and exerted a wide range of influence. In Thailand, the Romance of the Three Kingdoms has achieved good communication effect (Jin, 2013), as a result of the active feedback of "Gatekeeper" and "Opinion Leader", as well as the "Diffusion of Innovations". The gatekeeper decides what information should move past them (through the information "gate") to the group or individuals. Opinion leaders are individuals who exert a significant amount of influence within their network and who can affect the opinions of connected individuals. Diffusion of innovations is a model that attempts to describe how novel products, practices, or ideas are adopted by members of a social system. In the communication process of the Romance of the Three Kingdoms, Chaophraya Phrakhlang Hun et al. played an important role in the aspect of "Gatekeeper" and "Opinion Leader", in addition to the "Diffusion of Innovations".

Although the Romance of the Three Kingdoms has been widely disseminated in countries all over the world, especially adored by the people of Asian countries, its communication effect in Western countries is not ideal. The translation history of the Romance of the Three Kingdoms in North America is not so long as that in Japan, North Korea, Vietnam, Thailand and other Asian countries, where there is always more than one complete translation. In European countries, the Romance of the Three Kingdoms has English and French translation versions. Apart from English and French complete translation versions, the Romance of the Three Kingdoms is not translated into other languages completely (Wang, 2006).

\section{PROBLEMS OF COMMUNICATION}

Although the Romance of the Three Kingdoms is widely disseminated in various countries around the world, there are still some problems in the communication process. For instance, its acceptance in the English-speaking world is not optimistic.

Judging from the actual communication of ancient Chinese novels, it is not that the best quality Chinese civilization as we think has been properly disseminated overseas. What's more, the communication of Chinese civilization overseas is not original and static, and needs improvement (Liu, 2007). Furthermore, the existing foreign translation studies of the Romance of the Three Kingdoms are sporadic and lack of systematicity. Moreover, the existing researches only focus on translation introduction, translator research, translation strategies and other traditional translation studies at 
language and text level. As a result, the researches about the Romance of the Three Kingdoms are far from sufficient in depth and width, mainly focused on Moss Robert's version (Chen, 2015). Researchers should pay attention to more translation versions, conducting comparative studies of multiple translations. Although more researchers study the spread and acceptance of the Romance of the Three Kingdoms, few researches concentrate on its communication in English-speaking world. By searching the communication of the Romance of the Three Kingdoms on CNKI and Web of Science, the author found that there are obviously insufficient researches on its actual communication in Western society.

\section{CONCLUSION}

The Romance of the Three Kingdoms has spread wildly around the world through diverse forms of communication, whose communication strategy has certain reference significance for Chinese literature to go out. However, there are still some problems in the communication of the Romance of the Three Kingdoms, such as not receiving good communication effect in the English-speaking world. Therefore, the communication research of the Romance of the Three Kingdoms can be carried out from the aspects of communication strategy, audience research, acceptance, feedback, and multimodality to promote the in-depth research and communication of the Romance of the Three Kingdoms. According to the problems and deficiencies in the communication process of the Romance of the Three Kingdoms, the author puts forward the following suggestions based on the core concepts of communication studies:

(1) Promote the diversification of communicators. Domestic translators can cooperate with foreign translators or researchers to publish new translation versions of higher quality. In addition, the government and publishing houses make joint efforts to promote the communication of the Romance of the Three Kingdoms. Therefore, forming multi-level and step-like communicators fosters the maximum communication of the Romance of the Three Kingdoms.

(2)Facilitate the popularization and civilianization of the communication content. Aimed at different readers and their aesthetics, researches should be conducted on their cultural mentality and reader classification (Wang, 2012). Publish different versions according to different readers, such as ordinary readers and academic readers, thus promoting the localization, popularization and civilianization of the Romance of the Three Kingdoms and making it better spread.

(3) Accelerate diverse communication channels and use multimodal communication forms. In addition to textual form, the Romance of the Three Kingdoms can also be disseminated by means of mass media, such as radio, TV shows, small videos, animation, games and movies, so that people at different levels around the world will get to know the Romance of the Three Kingdoms, which can make it better spread and accepted around the world.

(4) Strengthen the research on readers' acceptance. Most papers talk about experience when referring to the reader acceptance of different translations. It is recommended to investigate the acceptance of different editions of the Romance of the Three Kingdoms by readers in English-speaking countries comprehensively, such as using questionnaire surveys, individual interviews, etc. By these means, examine the acceptance of different English translations in English-speaking countries. 
Furthermore, analyze the linguistic, cultural and social reasons for readers' different acceptability in different times, so as to promote a wilder spread of Chinese classics.

The Romance of the Three Kingdoms is an excellent representative of Chinese culture, and its communication will help Chinese culture go out to the world. In order to better promote its communication in the West, it is necessary for Chinese to truly spread it to Western society with the help of local Westerners. Measures should be made to promote the communication of the Romance of the Three Kingdoms, such as promoting the diversification of communicators, facilitating the popularization of the communication content and accelerating diverse communication channels, as well as using multimodal communication forms.

\section{ACKNOWLEDGEMENTS}

This work was supported by the Hubei Provincial Department of Education, P.R.China [Grant No.: 19ZD021; and Grant No.:18Y056]; the Institute of Science and Technology Development, Yangtze University, P.R.China [Grant No.:2018csz07]; and the Advantageous and Characteristic Humanities of "Modern Education and Jingchu Culture Research", Yangtze University [Grant No.: 2018YYY10]

\section{References}

[1] Besio, K., \& Tung, C. Three Kingdoms and Chinese Culture[M].State University of New York Press, 2007.

[2] Bo, H. Illustrated the Romance of the Three Kingdoms[M].Beijing: Central Compilation \& Translation Press, 2009.

[3] Cao, W. Overseas Sinologists and Chinese Modern and Contemporary Literature Translation and Publishing[J]. Publishing Journal, 2017, 25(03): 114-118.

[4] Chen, T. A Study on the English Translation of Cultural Items in the Romance of the Three Kingdoms[D]. Hunan Normal University, 2015.

[5] Chen, T. The overseas communication and enlightenment of classical literature: Taking the Romance of the Three Kingdoms as an example[J]. Social Scientist, 2017(09): 145-148.

[6] Dong, L. The core theories and concepts of communication[M]. Peking University Press, 2008.

[7] Guo, Q. \& Luo, H. Research on the communication of the Romance of the Three Kingdoms in Japan and South Korea[J].Journal of Ezhou University, 2014, 21(7): 46-47.

[8] Han, X. The Communication of Chinese Culture in Malaysia-Taking the Romance of the Three Kingdoms as an example[J]. International Sinology, 2015(03): 61-66+202.

[9] Jin, Y. Analyze the communication effect of the Romance of the Three Kingdoms in Thailand_-From the perspective of "feedback" of cross-cultural literary communication[J]. Southeast Asian Studies, 2013(02):107-111.

[10] Liu, Y. Several problems in the communication of ancient Chinese novels outside the territory[J]. Journal of Shanghai Normal University (Philosophy and Social Sciences Edition), 2007(05): 31-39.

[11] Mo, H. A Study on the Acceptance of Characters in the Romance of the Three Kingdom in Vietnam[D]. South China University of Technology, 2017.

[12] Ren et al. The Romance of the Three Kingdoms is popular in Asia[J]. Newspapers and Magazines,2006(07):65-67.

[13] Wang, H. English Translation of Chinese Classics: Achievements, Problems, and Countermeasures[J].Foreign Language Learning Theory and Practice, 2012(03): 9-14. 
[14] Wang, L. Chinese Classical Novels, Operas and Masterpieces Overseas, Xuelin Publishing House, 1988 edition, pages 8-9.

[15] Wang, P. Research on the Communication of Novels in Ming and Qing Dynasties, Shandong University Press, 2006 edition, p. 70.

[16] $\mathrm{Wu}, \mathrm{J}$. The communication and research of the Romance of the Three Kingdoms in North America[D]. Shaanxi University of Technology, 2018.

[17] Yan, B. The influence of Chinese fiction on Vietnam. Claudine salmon. Traditional Chinese Novels in Asia: 17th to 20th Century[C]. Translated by Chen Haiyan, Hanoi: Hanoi Science Press, 2004.

[18] Yang, L \& Deng, Y. A brief analysis of the reasons for the wide communication of the Romance of the Three Kingdoms in Thailand[J]. Around Southeast Asia,2011(01):57-59.

[19] Yu, L.The Communication and Influence of the Romance of the Three Kingdoms in Vietnam[J]. Journal of Baise University, 2020, 33(03):75-80. 